\title{
Numerical Analysis of Twin-Roll Casting of Strips With Profiled Cross-Section
}

\author{
Serhii Bondarenko ${ }^{a}$, Mykhailo Stolbchenko ${ }^{b}$, Mirko Schaper $^{b}$, Olexandr Grydin $^{b *}$ (D) \\ ${ }^{a}$ Chair of Metal Forming, National Metallurgical Academy of Ukraine, 49600, Dnipro, Ukraine \\ ${ }^{b}$ Chair of Materials Science, Paderborn University, 33098, Paderborn, Germany
}

Received: December 15, 2017; Revised: February 18, 2018; Accepted: March 09, 2018

\begin{abstract}
The relatively high production costs of innovative materials with tailored properties such as Tailor Welded Blanks, Patchwork Blanks, Tailor Heat Treated Blanks and Tailor Rolled Blanks are responsible for a growing interest in new cost-effective production methods. One of the promising energy-saving and environmental friendly technologies for the production of tailored blanks is twin-roll casting. In the study a new alternative method for twin-roll casting of strips with profiled cross-section is proposed, which uses one or more preloaded endless steel strips with an antiadhesive coating for profiling of the formed strip on a pair of the common cylindrical shells. As a primary stage for the practical process design, numerical simulation of the process using the finite element software package ANSYS is realized. In this way, dependencies of the strip elements outlet temperature, deformation zone length and elements outlet speed on the varied strips thickness and total solidification-deformation zone length are established. Based on the simulation results, a procedure for the twin-roll casting process design is suggested.
\end{abstract}

Keywords: strip, twin-roll casting, profiled cross-section, aluminum, numerical simulation.

\section{Introduction}

Nowadays, the application of lightweight materials and optimized lightweight products is one of the promising ways of enhancements in different industrial branches such as transport, building or aerospace. The implementation of lightweight materials, for example for car body components, reduces the fuel consumption and, consequently, the amount of emitted pollutants. Another way to decrease the weight of constructions using common materials lies in their smart design: The properties of a part have to be inhomogeneous and fitted to the load path in response to applied forces.

This approach has been already implemented in bulk production of sheet metal products for the automotive industry using different technologies such as application of Tailor Welded Blanks (TWB), Patchwork Blanks (PB), Tailor Heat Treated Blanks (THTB) and Tailor Rolled Blanks (TRB) ${ }^{1-2}$.

The TWB are produced by butt welding two or more strips of different thickness and/or steel grades together. The production method for the PB is similar to the previous one, but in this case one strip overlaps another and locally reinforces the initial strip of a constant thickness. However, the heat from a welding source affects the microstructure and mechanical properties of TWB and PB in the heat affected zones. Due to the fact, an additional heat treatment of TWB and PB is required.

The THTB are produced using special equipment that allows variations in heat treatment modes on the different strips elements. It enables adjustment of tailored mechanical properties in strips with a constant thickness ${ }^{3}$. However, the necessity to use the special equipment in the production of THTB results in a growth of production costs and in a high price of corresponding products.

The TRB are manufactured by means of plastic deformation of sheets in special rolling mills. During this process strips of the same material with variable thicknesses along the rolling direction or across the width are formed ${ }^{4}$. The last type of TRB cannot be produced in a single pass due to an inhomogeneous metal flow that results in a non-controllable distortion of the part. The need to apply the incremental forming operations with low deformation per a pass results in a high duration and a low productivity of the technology.

All disadvantages of the mentioned above manufacturing methods restrict the application of tailored blanks in bulk production in spite of a high industrial demand on such constructive elements. The main issue for today is the search for a technology to manufacture innovative products with tailored properties and with reduced production costs. This production method must additionally correspond to the growing demand of decreased pollution and reduced energy consumption at metal processing. Such a technology will significantly increase the competitiveness of the tailored sheet products in the world market.

One of the environmental friendly technologies that allows production of sheets of steel or light metals as well, with reduced energy consumption and decreased manufacturing costs is direct thin strip casting by means of twin-roll units ${ }^{5}$. Over the past decades, this technology has also been proven to produce steel-steel ${ }^{6}$, aluminumsteel $^{7-8}$ or magnesium-aluminum ${ }^{9}$ clad strips. That's why twin-roll casting is a good alternative to rolling ${ }^{10}$ for the 
production of thin strips with profiled cross-section, which are a class of the Tailor Rolled Blanks.

In 2011, Daamen et al first described the possibility of profiled steel strips manufacturing on a laboratory scale by means of the twin-roll casting ${ }^{11}$. The strips of an austenitic steel 1.4301 with a thickness difference in thick and thin elements amounted to $1.0 \mathrm{~mm}$ were successfully produced directly from the melt. Thus, the thickness of the thick and thin strip elements was $2.7 \mathrm{~mm}$ and $1.7 \mathrm{~mm}$, respectively. Two water-cooled on the inside rolls with corresponding profiled shells were used as the tool for the tailored strip formation. However, the proposed manufacturing method requires application of individual tool sets for every variation of the strip cross-section shape. Due to high costs of the shells, which are made of a special high-strength copper alloy with a relatively thick nickel coating, an industrial implementation of the technology is restricted.

The twin-roll casting process is quite complicated, therefore for analyzing of its conditions FE-simulation is widely applied. In 2009, Ju et al investigated the influence of the process parameters on the deformation zone length and, consequently, on the roll separating force using modeling with the finite element (FE) software package ANSYS $^{13}$. The study was carried out to determine the influence of the plastic straining at twin-roll casting on the probability of crack formation in the near-surface regions of strips of the magnesium alloy AZ31. It has been established that the stress caused by the plastic reduction of material has a greater influence on the quality of the strip than the thermal stress. It has been proven that continuous monitoring and controlling of the roll separating force during the process can significantly improve the quality of the strip and help to avoid crack formation.

Sahoo et al described and investigated the effect of casting rate and melt superheat in the twin-roll casting of an $\mathrm{Al}-33 \mathrm{Cu}$ alloy on conditions of the strip formation using the same software ${ }^{14}$. It has been shown that increasing of these parameters reduces the deformation zone length, because the time needed for solidification of the strip becomes longer. Such conclusions were made by analyzing the microstructures of the strips obtained at different values of investigated parameters. Kang and $\mathrm{Kim}^{15}$ used ANSYS to numerically analyze the influence of the twin-roll casting parameters on the stress state of the casting rolls. The data obtained in the framework of the study allowed determination of an optimal range of process parameters to extend the service life of the tool. Stolbchenko et al, aided by the same software, carried out a theoretical study of the twin-roll casting parameters influence, such as melt temperature, casting rate, strip thickness and length of the solidification-deformation zone, on the plastic strain and temperature of a strip of an aluminum alloy EN AW6082 at the roll caster outlet ${ }^{16}$. A correlation analysis of the obtained data regarding to temperature distribution in the solidification-deformation zone and position of the solidification front shape allowed to develop an empirical approach for a layout of the process parameters in order to achieve a desired plastic strain of the metal. Presented data demonstrates symmetrical conditions of the strip forming that is typical for vertical twin-roll casting. This fact is explained by identical cooling conditions on both shells.

Another work of Stolbchenko et al was devoted to numerical analysis of the twin-roll casting of aluminumsteel clad strips by means of the software ANSYS ${ }^{17}$. In this continuous process, a thin solid steel strip is fed from an uncoiler into the roll gap together with aluminum melt ${ }^{7}$. The product of the process is an aluminum-steel clad strip with a high adhesive strength due to formation on the interface between steel and aluminum of a continuous and thin layer of intermetallic phases of a thickness about $3 \mu \mathrm{m}$. The presence of the solid steel strip pressed to the surface of one of the rolls creates an additional thermal resistance between the aluminum melt and the tool. This feature has been taken into account during modeling of the process. It has been shown that the kissing point is moving from the centerline of the solidification-deformation zone in direction of the fed steel strip. The conditions of clad strip formation become asymmetric.

It should be mentioned that software packages other than ANSYS are also used for the numerical analysis of twinroll casting. For example, Lee et al realized the simulation of the processing of strips of an aluminum alloy AA7075 by means of the FE software Deform ${ }^{18}$. The corresponding study proved that the roll separating force decreases with an increasing casting rate and with higher melt temperatures. The influence of the parameters on the strip outlet temperature has a backwards character. Summarized, it has been concluded that the kissing point at such conditions is moving closer to the outlet from the roll gap. It results in a decreasing amount of the plastic reduction of metal in the deformation zone.

Vidoni et al also used numerical simulation to analyze the temperature distribution over the width of the profiled strip of an austenitic steel 1.4301 in the twin-roll casting process ${ }^{19}$. Variation of the thickness of the nickel coating layer on the shells has been considered in order to homogenize the temperature of the strip's elements of different thickness. The implementation of the established results for practical roll design allows to obtain a more homogeneous microstructure of material through the cross-section of the strip.

In this paper, an alternative method for profiling of the shell's surface is considered. It's suggested to use a device, which uses one or more preloaded endless steel strips with an antiadhesive coating for the profiling of the formed strip on a pair of the common cylindrical shells ${ }^{12}$. This solution has been shown schematically in Fig. 1, with $\mathrm{F}$ as an indication for the preloading tension force. 


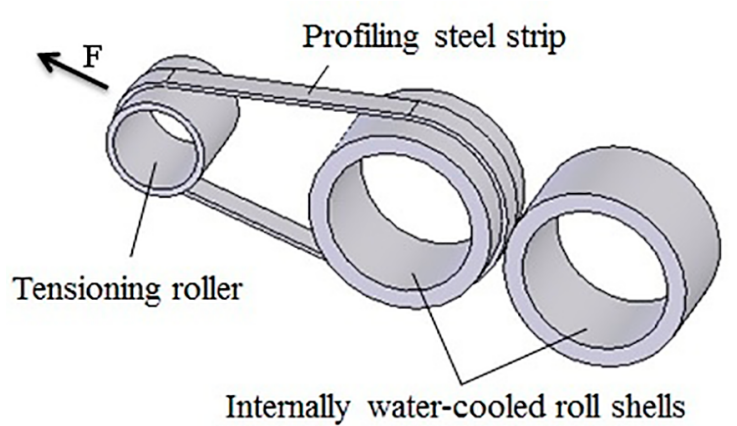

Figure 1. Scheme of the tool for twin-roll casting of profiled strips using cylindrical shells

Due to the complexity of the practical realization of twin-roll casting, caused by a combination of rapid solidification and following deformation of metal in one production step, the approach with an initial analysis of the process by using numerical simulation is widely used. The most important and often analyzed parameters, which effect the stability of the process and the resulting strip quality, are plastic strain of the metal and temperature of the strip at the outlet from the roll gap.

The research results described above show that the numerical simulation of the twin-roll casting process in its different variants is a powerful tool for the determination of optimal process parameters, which can help to improve the interaction of the conditions between the shells and the processed metal and the quality of the strips as well. Thus, getting an estimation of the optimal combination of parameters using FE-simulation of the new twin-roll casting process that allows manufacturing of strips with profiled cross-sections directly from the melt is the main goal of this study.

\section{Numerical modeling of the new twin-roll casting method}

In the same manner as it has been realized in works ${ }^{13-18}$, the modeling has been provided by means of the FE software package ANSYS. Besides the already mentioned publications, this software has also been successfully used to simulate twin-roll casting of strips of aluminum and aluminum alloys ${ }^{20}$, various steels $\mathrm{s}^{21-22}$ and magnesium alloys ${ }^{23}$.

The developed model considers the material as a viscous incompressible fluid with variable properties. Due to the fact that the first practical experimental trial on twin-roll casting of strips with profiled cross-sections is planned to bedone using a technical pure aluminum EN AW-1050, which is well-known in twin-roll casting of flat strips, this material has been chosen for the first series of theoretical investigations, too. Used for the simulation relevant metal properties of the aluminum alloy EN AW-1050 are specified in Table 1. The considered dependence of the material's viscosity on its aggregate state enables simulation of the metal flow in liquid and solid state using the same theoretical approach. For the calculation of the material properties in semi-solid state, between liquidus and solidus temperatures, the rule of mixture has been applied.

Table 1. Properties of the aluminum alloy EN AW-1050 used in the model

\begin{tabular}{lll}
\hline & Liquid state & Solid state \\
\hline Density, $\mathrm{kg} / \mathrm{m}^{3}$ & 2300 & 2700 \\
Thermal conductivity, $\mathrm{W} / \mathrm{m} \cdot \mathrm{K}$ & 80 & $200-400$ \\
Viscosity, Pa $\mathrm{s}$ & 0,012 & 100 \\
Threshold temperatures, ${ }^{\circ} \mathrm{C}$ & 657 (liquidus) & 646 (solidus) \\
\hline
\end{tabular}

The tool geometry in the model corresponds to the parameters of the experimental twin-roll casting unit described $\mathrm{in}^{24}$. The diameter of the internally water-cooled roll shells is $370 \mathrm{~mm}$, the length of the roll's barrel is $200 \mathrm{~mm}$. The thickness of the shells, made of X38CrMoV5-6 steel, amounts to $15 \mathrm{~mm}$.

To simplify the model and reduce the calculation time, the internally water-cooled roll shells, the profiling strip and the solidification-deformation zone are represented as two-dimensional. The heat and mass transfer in the transversal direction along the roll barrel were neglected. The tool, solidification-deformation zone and strip were considered as sections of different profiled elements. The heat transfer coefficient between the metal and the profiling strip has been chosen on the basis of own experimental data and amounts to $3000 \mathrm{~W} / \mathrm{m}^{2} \cdot \mathrm{K}$. The heat transfer coefficient between the metal and the water-cooled shells amounts, for a strip thickness of $2 \mathrm{~mm}$ to $17800 \mathrm{~W} / \mathrm{m}^{2} \cdot \mathrm{K}$, for a strip thickness of $3 \mathrm{~mm}$ to $15000 \mathrm{~W} / \mathrm{m}^{2} \cdot \mathrm{K}$ and for a strip thickness of $4 \mathrm{~mm}$ to $13100 \mathrm{~W} / \mathrm{m}^{2} \cdot \mathrm{K}$. The heat transfer coefficient on the inner water-cooled surface of the internally water-cooled roll shells is $10000 \mathrm{~W} / \mathrm{m}^{2} \cdot \mathrm{K}$. The temperature of the coolant was set equal to $20^{\circ} \mathrm{C}^{25}$.

The shape of profiled in the cross-section strip, which was selected for numerical analysis, is depicted in Figure 2. The unchanged twin-roll casting parameters used for the simulation were a casting rate of $3.25 \mathrm{~m} /$ min, a thickness of the steel profiling strip of $0.5 \mathrm{~mm}$ (s. Fig. 1) and a melt temperature of $660^{\circ} \mathrm{C}(933 \mathrm{~K})$. The combinations of the parameters, which have been varied in the study's framework, are shown in Table 2.

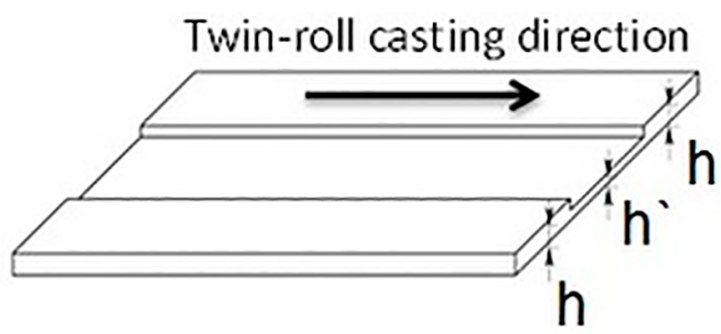

Figure 2. Schematic visualization of strip with profiled cross-section used for the simulation 
Table 2. Values of varied twin-roll casting parameters for simulation of profiled strips manufacturing.

\begin{tabular}{lcccccc}
\hline Parameters set № & 1 & 2 & 3 & 4 & 5 & 6 \\
\hline Thickness of thin element (h'), mm & 0.5 & 1.0 & 1.5 & 2.0 & 2.5 & 3.0 \\
Thickness of thick elements (h), mm & 1.0 & 1.5 & 2.0 & 2.5 & 3.0 & 3.5 \\
Length of the solidification-deformation zone, $\mathrm{mm}$ & \multicolumn{2}{c}{$25,35,60$} & & \\
\hline
\end{tabular}
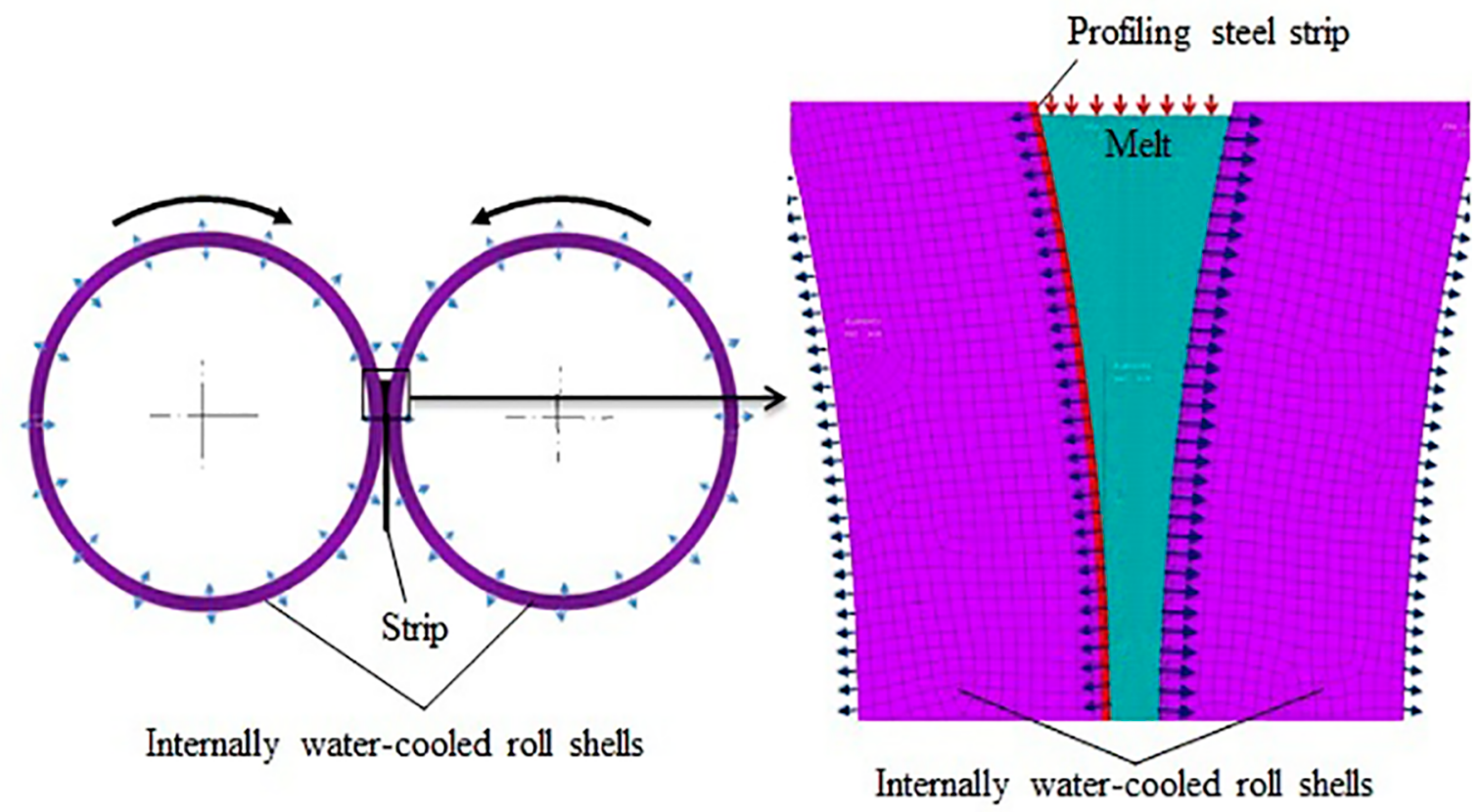

Figure 3. Overall arrangement and boundary conditions in the twin-roll casting model for thin element of the profiled strip

The following boundary conditions in the FE-model were arranged (s. Fig. 3): Cooling on the inner side of internally water-cooled roll shells occurs by forced convections. The outside of roll shells and the strip surface after its outlet from the roll gap are cooled by free convection. The melt temperature on the surface of the solidification-deformation zone is constant. Cooling of the metal in the solidification-deformation zone occurs by forced convection between the metal and the roll shells and by thermal conductivity corresponding to Fourier's law.

\section{Results of numerical simulation}

At the numerical simulation of profiled strip twin-roll casting in the section of the thinner element of the strip, the previously described phenomenon of an asymmetric strip formation was also observed. The kissing point moves from the centerline of the solidification-deformation zone into the direction of the profiling steel strip (s. Fig. 4). This section of the melt pool corresponds to the section of the profiled strip's element with the thickness h' (s. Fig. 2). Such calculated temperature distributions for different elements of profiled strips and for varied twin-roll casting conditions allow to identify the location of the kissing point, the corresponding lengths of solidification and deformation zones and the mean temperature of the strip outlet from the roll gap. Besides, data about velocity of the strip outlet for the different profiled elements have been analyzed.

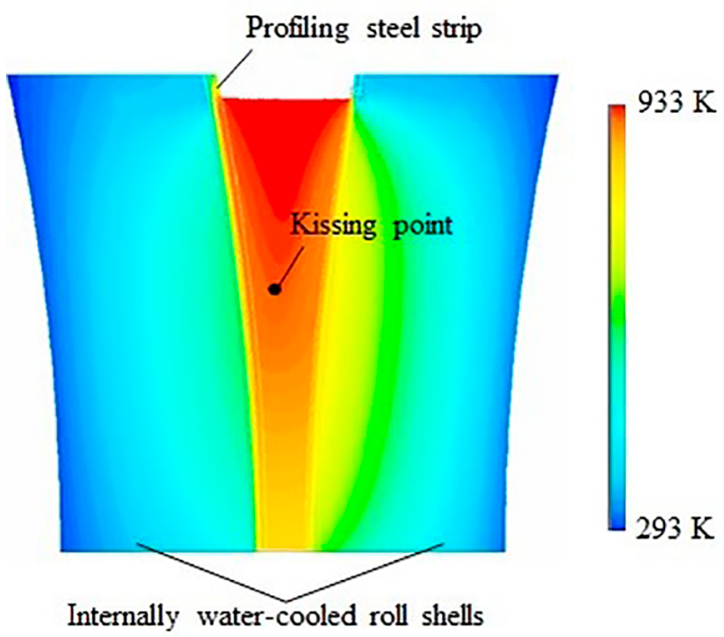

Figure 4. Temperature distribution in the thin element of the twin-roll cast profiled aluminum strip, established by a numerical simulation

The generalized results obtained by numerical simulation are shown in the form of graphs in Fig. 5 and in Fig. 6. 


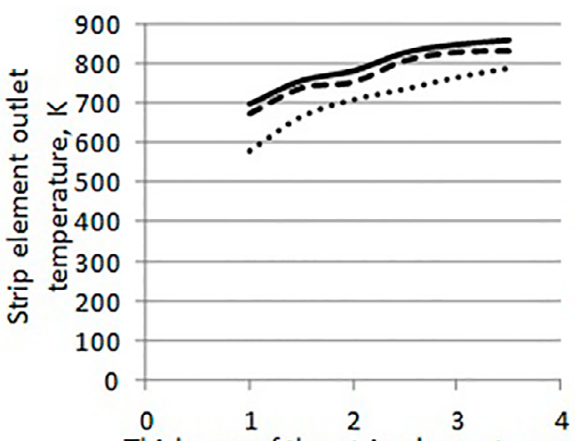

Thickness of the strip element, $\mathrm{mm}$

a)

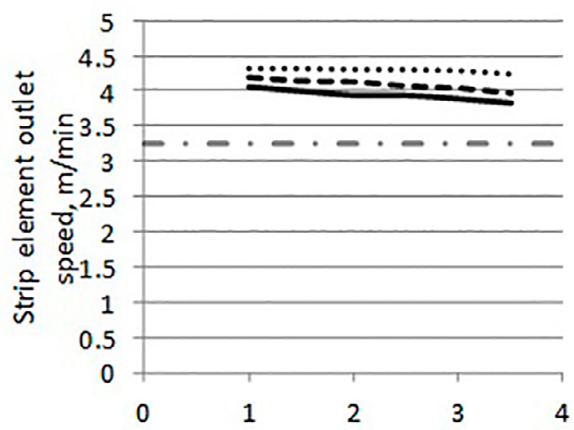

Thickness of the strip element, $\mathrm{mm}$ c)

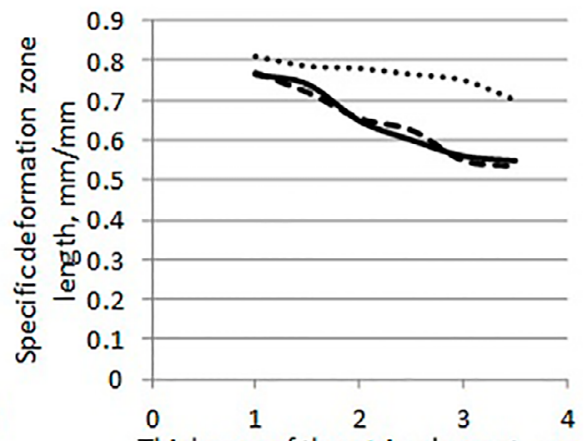

Thickness of the strip element, $\mathrm{mm}$

b)

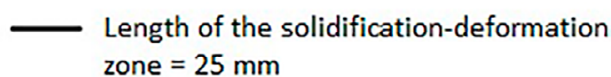
zone $=25 \mathrm{~mm}$

- Length of the solidification-deformation zone $=35 \mathrm{~mm}$

Length of the solidification-deformation zone $=60 \mathrm{~mm}$

- . Twin-roll casting speed

Figure 5. Dependences of the strip element outlet temperature (a), specific deformation zone length (b) and element's outlet speed (c) on the thickness of the thick element of the strip

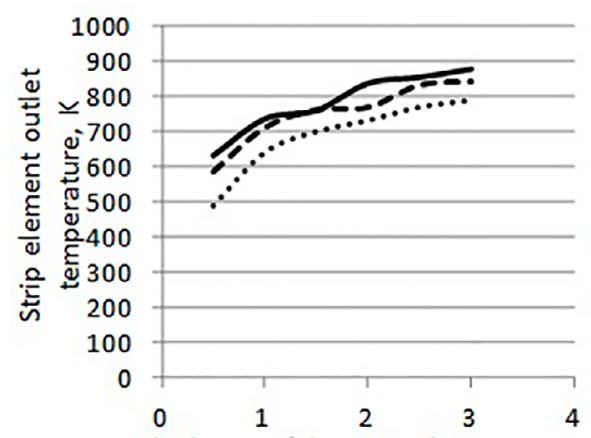

Thickness of the strip element, $\mathrm{mm}$

a)

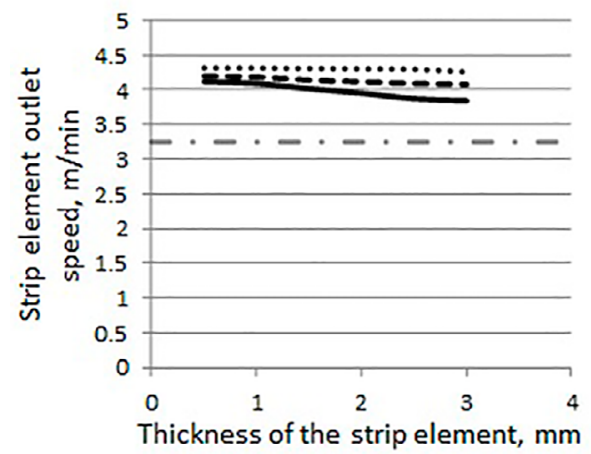

c)

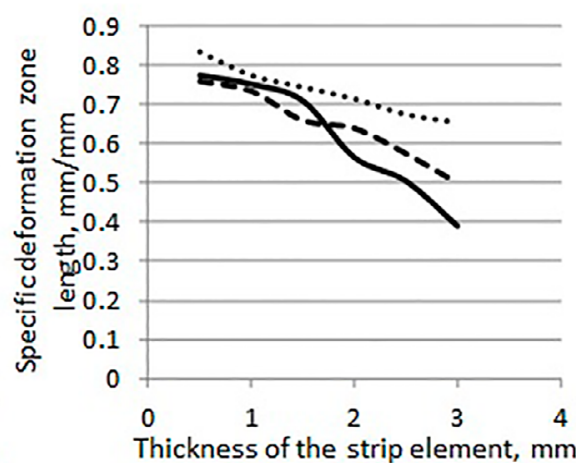

b)

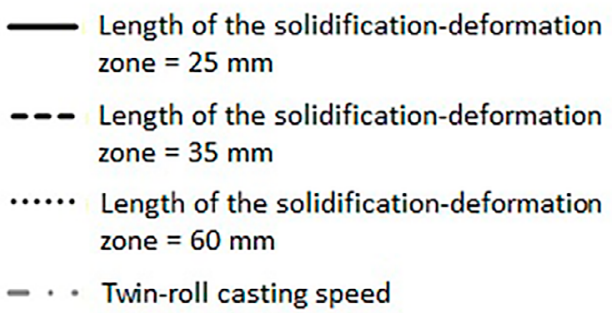

-.. Twin-roll casting speed

Figure 6. Dependences of the strip element outlet temperature (a), specific deformation zone length (b) and element's outlet speed (c) on the thickness of the thin element of the strip 
The data shows that increasing the strip elements' thickness leads to increasing of strip outlet temperature for these elements (Fig. 5a, Fig. 6a). This dependence is observed in the whole range of the solidification-deformation zone length used in the numerical simulation. It can be explained by an increasing of the melt volume in the space between the rolls and a necessity to remove more heat from the melt for the solidification of the metal. This effect also causes a decreasing of the deformation zone length. This is confirmed by the generalized data of specific deformation zone length dependence on the thickness of the strip elements (Fig. 5b, Fig. 6b).

The specific length of the deformation zone represents the ratio of the deformation zone length to the total length of the solidification-deformation zone. Thus, the maximum value of the specific deformation zone length corresponds to the minimal thickness of thick and thin elements of the profiled strip ( $1.0 \mathrm{~mm}$ and $0.5 \mathrm{~mm}$, respectively).

Besides, simulation results show decreasing of the strip element outlet velocity with increasing of its thickness (Fig. 5c and Fig. 6c). This can be explained by the reduction of the deformation zone length and decreasing of plastic metal strain, respectively.

\section{Process design for twin-roll casting of profiled strips}

The applied approach for the simulation of twin-roll casting of strips with profiled cross-section using a twodimensional process model allows to characterize the conditions of strip formation on the elements of different thicknesses. However, in the real three-dimensional process, there is an interaction between the solidified strip's elements during their deformation, which can result in an appearance of tensile stress in the transition strip areas. This stress can cause distortion or even cracking of the strip.

The same problem is well-known at hot extrusion of complex aluminum shapes with elements of different thickness. In the case of hot extrusion, a general principle of the equal outlet velocity ensuring for all of elements of a profile is used ${ }^{26-28}$. The adjustment of the outlet velocities for different shaped elements is reached by corresponding calibration of bearing length and setting of pre-chamber configuration in the stage of extrusion die design. Sticking to the rule enables manufacturing of very complex aluminum shapes without profile distortion. This fact is proven by the longtime industrial practice.

In a similar manner, this approach can be implemented for the twin-roll casting of profiled strips. Homogenization of the strip elements outlet velocities for each profile element independently, has to result in minimization of tensile stress in transition strip areas. The main process parameter, that enables a flexible adjustment of strip elements velocities in a wide range, is the solidification-deformation zone length (s. Fig. 5b, Fig. 6b). The individual setting of this parameter for each element of a profiled strip is possible, when nozzles with corresponding shaped tips are used.

In Fig. 7 an example of determination of the optimal solidification-deformation zone length for twin-roll casting of a strip with thick-thin-thick-cross-section (s. Fig. 2) with elements thicknesses of $1.5 \mathrm{~mm}-1.0 \mathrm{~mm}-1.5 \mathrm{~mm}$ at a roll's revolving speed of $3.25 \mathrm{~m} / \mathrm{min}$ is presented. The horizontal dot and dash lines in the diagram mark predicted outlet velocities of the thin strip elements for three different variants of the solidification-deformation zone lengths, while the solid line corresponds to dependence of the outlet velocity of the thick strip elements on the solidification-deformation zone length. The intersections between horizontal dot and dash lines and

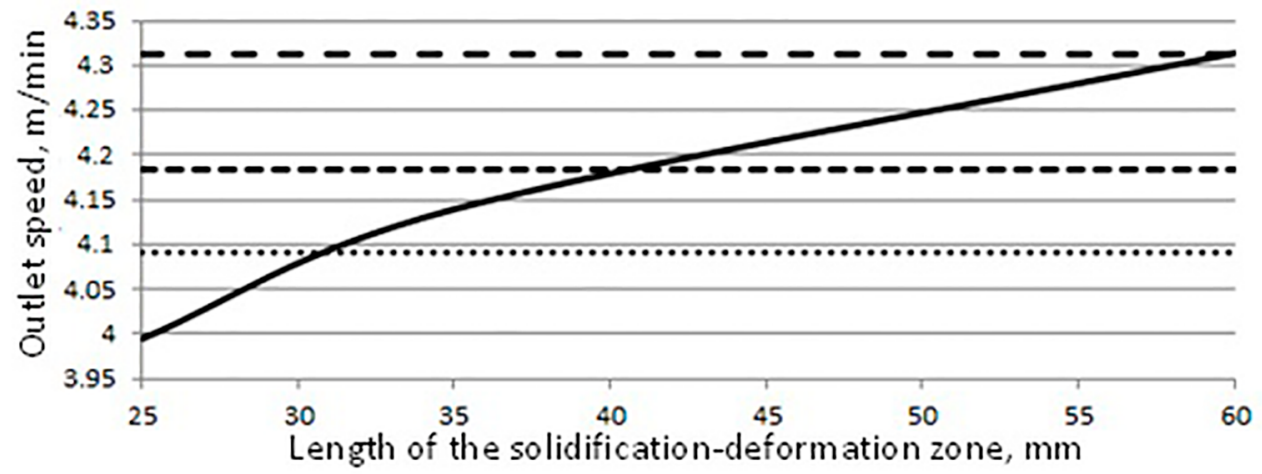

\section{- Speed of thick (h) strip element \\ ..... Speed of thin (h') strip element (length of the solidification-deformation zone $=25 \mathrm{~mm}$ ) \\ - - Speed of thin (h') strip element (length of the solidification-deformation zone $=35 \mathrm{~mm}$ ) \\ - - Speed of thin (h') strip element (length of the solidification-deformation zone $=60 \mathrm{~mm}$ )}

Figure 7. Determination of the optimal solidification-deformation zone length for thin and thick elements of a strip with profiled crosssection for the rolls speed of $3.25 \mathrm{~m} / \mathrm{min}$ 
the solid line give information about possible combinations of solidification-deformation zone lengths for thick and thin strip elements, which enable a straight outlet of the profiled strip from the roll gap. In the following way, the solidification deformation zone length of the thin element of $25 \mathrm{~mm}$ corresponds a solidification deformation zone length of the thick elements of $31 \mathrm{~mm}$. The outlet velocities' balance is also possible at a combination of the solidification-deformation zone lengths of $35 \mathrm{~mm}$ and $41 \mathrm{~mm}$, respectively.

An interesting situation occurs at the solidificationdeformation zone length of $60 \mathrm{~mm}$ : The outlet velocities on different strip elements become equal at the same value of the solidification-deformation zone lengths for both thick and thin strip elements. This parameter could be seen as the best possible, due to a simplification of the nozzle tip design. However, there is a relatively high plastic reduction of metal at the long solidification-deformation zone. It reaches $89 \%$ for the thick and $88.5 \%$ for the thin elements of the strip. Accordingly, provoked increasing of the roll separating force and the loads on the tool have to be taken into account at the technological process design.

In practice, individual value of solidification-deformation zone length for the elements of profiled strip can be achieved through the use of a nozzle with a shaped tip. This nozzle should have a stepped tip that corresponds to the shape of steel profiling strip. The nozzle tip has to be in a direct contact with the rolls and profiling steel strip surfaces. In such a manner the solidification-deformation zone length can be adjusted individually for all profiled strip elements.

\section{Conclusions}

Twin-roll casting technology is a reasonable alternative for the production of strips with profiled cross-section. The application of the technology will enable energy saving and ecological improvements. In this work, a new manufacturing method for twin-roll casting of profiled strips is suggested, which uses one or more preloaded endless steel strips with an antiadhesive coating for profiling of the formed strip on a pair of the common cylindrical shells. The study on the two-dimensional numerical simulation of the considered manufacturing method provides data about dependencies of the strip element outlet temperature, deformation zone length and elements outlet velocity on the thickness of the strip elements and on the length of the solidification-deformation zone at twin-roll casting of an aluminum alloy of technical purity.

It is suggested to use the principle of the equal outlet velocities for all of the elements of a profiled strip for the technological process design, which enables manufacturing of strips without shape distortion. The flexible adjustment of strip elements velocities in a wide range is achievable by an individual setting of the solidification-deformation zone length, which can be technically realized using nozzles with a shaped tip. Based on the numerical simulation results, an example of optimal parameter selection for twin-roll casting of profiled strips with thicknesses of $1.5 \mathrm{~mm}$ in thick elements and of $1.0 \mathrm{~mm}$ in thin elements is described in detail.

\section{References}

1. Merklein M, Johannes M, Lechner M, Kuppert A. A review on tailored blanks - Production, applications and evaluation. Journal of Materials Processing Technology. 2014;214(2):151-164.

2. Pallet RJ, Lark RJ. The use of tailored blanks in the manufacture of construction components. Journal of Materials Processing Technology. 2001;117(1-2):249-254.

3. Merklein M, Lechner M. Manufacturing Flexibilisation of Metal Forming Components by Tailored Blanks. In: Proceedings of the International Conference on Competitive Manufacturing; 2013 Jan 30- Feb 1; Stellenbosch, South Africa. p. 165-170.

4. Kopp R, Böhlke P. A New Rolling Process for Strips with a Defined Cross Section. CIRP Annals. 2003;52(1):197-200.

5. Ferry M. Direct Strip Casting of Metals and Alloys. Cambridge: Woodhead Publishing; 2006.

6. Münster D, Vidoni M, Hirt G. Effects of Process Parameter Variation on the Bonding Strength in Clad Steel Strips by Twin-Roll Strip Casting. Material Science Forum. 2016;854:124-130.

7. Grydin O, Gerstein G, Nürnberger F, Schaper M, Danchenko V. Twin-roll casting of aluminum-steel clad strips. Journal of Manufacturing Processes. 2013;15(4);501-507.

8. Chen G, Li JT, Yu HL, Su LH, Xu GM, Pan JS, et al. Investigation on bonding strength of steel/aluminum clad sheet processed by horizontal twin-roll casting, annealing and cold rolling. Materials \& Design. 2016;112:263-274.

9. Bae JH, Prasada Rao AK, Kim KH, Kim JN. Cladding of $\mathrm{Mg}$ alloy with $\mathrm{Al}$ by twin-roll casting. Scripta Materialia. 2011;64(9):836-839.

10. Hirt G, Dávalos-Julca DH. Tailored Profiles Made of Tailor Rolled Strips by Roll Forming - Part 1 of 2. Steel Research International. 2012;83(1):100-105.

11. Daamen M, Förster T, Hirt G. Experimental and Numerical Investigation of Double Roller Casting of Strip with Profiled Cross Section. Steel Research International. 2011;Sp Ed:93-98.

12. Гридін О.Ю, Огінский Й.К, Бондаренко С.В, Шапер М. Пристрій для валкової розливки-прокатки профільованих штаб. Патент UA 113368, МПК (2006.01) B22D 11/06, В22D 11/10. Заявл.04.01.2016; опубл.10.01.2017, Бюл.1.

13. Ju DY, Hu XD, Zhao HY. Inelastic behavior and numerical analysis in twin-roll casting process of AZ31 alloy. Archives of Mechanics. 2009;61(3-4):229-239.

14. Sahoo S. Review on Vertical Twin-Roll Strip Casting: A Key Technology for Quality Strips. Journal of Metallurgy. 2016;2016:1038950. 
15. Kang CG, Kim YD. A thermal elastic-plastic finite-element analysis to roll-life prediction on the twin roll strip continuous casting process. Metallurgical and Materials Transactions $B$. 1997;28(6):1213-1225.

16. Stolbchenko M, Grydin O, Schaper M. Twin-roll Casting and Finishing Treatment of Thin Strips of the Hardening Aluminum Alloy EN AW-6082. Materials Today: Proceedings. 2015;2(Suppl 1):S32-S38.

17. Stolbchenko M, Grydin O, Samsonenko A, Khvist V, Schaper M. Numerical analysis of the twin-roll casting of thin aluminium-steel clad strips. Forschung im Ingenieurwesen. 2014;78(3-4):121-130.

18. Lee YS, Kim HW, Cho JH. Effect of Casting Parameters on Roll Separation Force during Twin Roll Casting. Procedia Engineering. 2014;81:1547-1552.

19. Vidoni M, Daamen M, Hirt G. Advances in the Twin-Roll Strip Casting of Strip with Profiled Cross Section. Key Engineering Materials. 2013;554-557:562-571.

20. Sahoo S, Kumar A, Dhindaw BK, Ghosh S. Modeling and Experimental Validation of Rapid Cooling and Solidification during High-Speed Twin-Roll Strip Casting of Al-33 wt pct $\mathrm{Cu}$. Metallurgical and Materials Transactions B. 2012;43(4):915-924.

21. Liu L, Liao B, Guo J, Liu L, Hu H, Zhang Y, et al. 3D Numerical Simulation on Thermal Flow Coupling Field of Stainless Steel During Twin-Roll Casting. Journal of Materials Engineering and Performance. 2014;23(1):39-48.
22. Fang Y, Wang Z, Yang Q, Zhang Y, Liu L, Hu H, et al. Numerical simulation of the temperature fields of stainless steel with different roller parameters during twin-roll strip casting. International Journal of Minerals, Metallurgy and Materials. 2009;16(3):304-308.

23. Hu XD, Ju DY, Zhao HY. Thermal flow simulation of twin-roll casting magnesium alloy. Journal of Shanghai Jiaotong University (Science). 2012;17(4):479-483.

24. Grydin OY, Ogins\&apos;kyy YK, Danchenko VM, Bach FW. Experimental Twin-Roll Casting Equipment for Production of Thin Strips. Metallurgical and Mining Industry. 2010;2(5):348-354.

25. Бондаренко СВ, Гридин АЮ, Столбченко МЮ, Шапер М. Определение коэффициента теплоотдачи в системе металл-валок при валковой разливке-прокатке алюминиевых сплавов. Метал и литье Украины. 2013;5;3-8.

26. Hardouin JP. Bearing Length Calculation by Control of Metal Flow Pressure. In: Proceedings of Fifth International Extrusion Technology Seminar; 1992 May 19-22; Chicago, IL, USA. p. 291-303.

27. Golovko O, Mamuzić I, Grydin O. Method for pocket die design on the basis of numerical investigations of aluminium extrusion process. Metalurgija. 2006;45(3):155-161.

28. Равин АН, Суходрев ЭШ, Дудецкая ЛР, Щербанюк ВЛ. Формообразующий инструмент для прессования и волочения профилей. Минск: Наука и техника; 1988. 